\title{
Garotas do velho Rio: \\ As personagens de Alceu Pena e seu pertencimento cultural a cidade do Rio de Janeiro'
}

\author{
Girls of the old Rio: \\ The characters of Alceu Penna and his cultural belonging to the city of \\ Rio de Janeiro
}

Daniela Queiróz Campos*

Resumo: O presente artigo aborda o pertencimento cultural das personagens da coluna Garotas do Alceu a cidade do Rio de Janeiro. A coluna circulou nas páginas da grande revista brasileira de variedades de meados do século XX - O Cruzeiro (19281975) - de 1938 a 1964. Garotas era o título da afamada coluna de pin-ups ilustrada pelo desenhista mineiro Alceu Penna. As personagens femininas traçadas por Penna semanalmente apresentavam aos leitores de $O$ Cruzeiro o cotidiano de jovens mulheres "modernas" em diferentes situações sociais que abarcavam novos modelos de sociabilidade urbana naquele Rio de Janeiro dos anos dourados - pós segunda Grande Guerra mundial.

Palavras-chave: imagem. revista. cidade.

\begin{abstract}
This paper discusses the cultural belonging of the Alceu Penna's column characters, the Girls or Garotas, to the city of Rio de Janeiro. The column circulated on the pages of the great Brazilian varieties magazine of the mid-twentieth century O Cruzeiro (1928-1975) - from 1938 to 1964. To so called Garotas constituted the renowned pin-ups column, which the drawer Alceu Penna illustrated. The female characters drawn by Penna presented weekly for the readers of the magazine the daily lives of young "modern" women in different social situations that encompassed new models of urban sociability of Rio de Janeiro's golden years - post Second World World War.
\end{abstract}

Keywords: image. magazine. city.

\footnotetext{
${ }^{1} \mathrm{O}$ presente artigo apresenta-se como desmembramento de pesquisa doutoral realizada junto ao Programa de Pós-Graduação em História da Universidade Federal de Santa Catarina sub a orientação da Professora Doutora Maria Bernardete Ramos Flores, tendo sido realizado um estágio doutoral na EHESS de Paris com o Professor Doutor Georges Didi-Huberman, ambos (doutorado e período de sanduiche) com bolsa CAPES.

* Pós-doutoranda École de Hautes Études en Sciences Sociales de Paris sob a supervisão do Professor Doutor Georges Didi-Huberman, bolsista CNPq.
} 


\section{As Garotas de O Cruzeiro}

Escrever sobre a coluna Garotas sem antes escrever sobre a revista da qual ela era parte integrante seria tarefa difícil. Não só pela coluna ter feito parte do projeto editorial e gráfico da revista, mas também porque $O$ Cruzeiro foi o suporte impresso em que ela circulou. Os leitores das Garotas eram também os leitores de O Cruzeiro. Segundo Roger Chartier (1999) a leitura em diferentes tipos de suportes resignifica a própria leitura. "Ler um artigo em um banco de dados eletrônico, sem saber nada da revista na qual foi publicado, nem dos artigos que o acompanharam, e ler o "mesmo" artigo no suporte original não é a mesma experiência” (CHARTIER, 1999, p.128). Diferentes suportes corroboram na construção de diferentes experiências, diferentes sentidos ao lido.

A revista Cruzeiro inicia sua circulação no ano de 1928, fora pensada para ser uma revista grandiosa, no formato tabloide (26 x $33 \mathrm{~cm}$ ) impressa em 4 cores em papel de alta qualidade. Inicialmente a revista ilustrada contava com colaboradores de porte, ótimos ilustradores, farta documentação fotográfica, além de constarem em seu sumário excelentes colunistas fixos. Escreviam na revista nomes como Mario de Andrade e Humberto Campos, suas ilustrações eram assinadas por Emilio Di Cavalcante, Anita Malfatti, Oswaldo Teixeira entre outros.

No final da década de 1920, ela já era um verdadeiro sucesso editorial. Eram anos prósperos para O Cruzeiro, que era considerada a "melhor e mais moderna" de então. E seu sucesso não estava localizado na sua cidade sede, o Rio de Janeiro, chegava de fato a todos os estados, onde obtinha níveis de vendas bastante satisfatórios. Em 1929, a tiragem semanal do periódico chegou ao número de 80 mil.

A revista $O$ Cruzeiro fazia parte do grupo de comunicação criado por Assis Chateaubriand, o qual a partir da década de 1930 começou a ser chamado de Diários Associados $^{2}$. Todavia, ainda no início daquela década, a tiragem da revista caiu assustadoramente - chegando a menos de 20 mil exemplares por edição semanal. Para revigorar o periódico o jornalista Alccioly Netto assumiu a secretaria de redação, as mudanças logo surtiram efeito. A revista começa a passar por gradativas

\footnotetext{
${ }^{2}$ No ano de 1930, em um artigo resposta ao então presidente da república Getúlio Vargas, Chatô utilizou pela primeira vez o termo nossos diários associados, nome que designaria sua rede nas décadas seguintes.
} 


\section{Revista Brasileira de História \& Ciências Sociais - RBHCS}

Vol. $8 \mathrm{~N}^{\circ}$ 16, Julho - Dezembro de 2016

transformações, ao explorar atualidades políticas, sociais e artísticas, reportagens elaboradas com as "sobras" fotográficas e com matérias dos jornais dos Diários Associados. O Cruzeiro foi tornando-se aos poucos mais atraente ao público feminino.

Leoni Serpa (2003) sublinha que aproximadamente 30\% das páginas da revista eram referentes ao imaginário feminino, que não compunha apenas um, mas vários perfis femininos (Bassanezi,1995). Essas imagens e mulheres eram uma das marcas de $O$ Cruzeiro. Ao longo dos 47 anos em que circulou em território nacional e no exterior, constava em seu sumário um sem-número de colunas voltadas para a mulher, a exemplo das colunas Da mulher para a mulher e Elegância e Beleza.

Outra marca da famosa revista eram as páginas de humor, constituindo cerca de 50\% do impresso. Boa parte destas colunas eram ilustradas por famosos desenhistas, como Alceu Penna, Millôr Fernandes, Péricles, Carlos Estêvão. O amigo da onça foi o personagem mais famoso de O Cruzeiro. Assinado por Péricles de Andrade Maranhão, o homenzinho com o rosto em formato oval e incrivelmente mal humorado, preconceituoso e conservador3 tornou-se o personagem mais famoso da caricatura no país (Silva, 1989).

As fotorreportagens - ao estilo gráfico das publicadas pela Life e Paris Match também se sobressaiam. Inúmeros foram os jornalistas que assinaram as grandiosas reportagens de $O$ Cruzeiro. Contudo, um merece destaque especial - David Nasser, que juntamente com o fotógrafo francês Manzon, produziu fotorreportagens marcantes para o periódico.

Ao longo de 20 anos, a revista $O$ Cruzeiro atingiu seu maior número de tiragem por edição, transformando-se em uma revista eclética, lida por homens e mulheres das mais diferentes idades. Convencionou-se chamar o sucesso do periódico de "milagre editorial", tendo em vista a exorbitante tiragem frente aos milhões de analfabetos existentes no Brasil na época. A tiragem por edição semanal chegou a 750 mil exemplares.

A revista $O$ Cruzeiro foi problematizada por esta pesquisa a partir das premissas do "documento-revista" de Maria Luiza Martins (2001). Para tal pesquisadora o objeto de investigação "documento-revista" possibilita ao historiador um registro múltiplo - registro textual e iconográfico de uma época. Nas muitas páginas da

\footnotetext{
3 Ver mais em: SILVA, Marcos Antônio da. Prazer e poder do amigo da onça 1943-1962. Rio de Janeiro: Paz e Terra, 1989.
} 


\section{Revista Brasileira de História \& Ciências Sociais - RBHCS}

Vol. $8 \mathrm{~N}^{\circ}$ 16, Julho - Dezembro de 2016

revista $O$ Cruzeiro podemos analisar e problematizar a sociedade, urbana e de classe média e alta, brasileira do século XX. Este “documento-revista” nos proporciona visualizar como aquela sociedade fora expressa nas páginas de uma de suas mais destacadas revistas.

A revista pesquisada foi analisada como uma prática de leitura aparentemente corriqueira, ou ordinária e caracterizada por ser amena, ligeira e pausada. Tal qual boa parte das revistas de atualidades, O Cruzeiro assinala-se como objeto de leitura não apenas associado ao espaço privado, sua leitura também fora visível em espaços públicos - como ambientes de trabalho, salas de esperas, entre outros - a circularidade é característica marcante do impresso das bancas de revistas.

De tal feita não podemos afirmar que todos os números da revista vendidos foram lindos, nem que um exemplar foi lido apenas por uma ou duas pessoas. Lembremos dos preceitos ensinados por Roger Chartier, sempre cauteloso ao trabalhar com a recepção e apropriação de livro e periódico. Para o historiador "todos os livros lidos não são livros possuídos” (CHARTIER, 2004, p.175), como nem todos os livros possuídos foram obrigatoriamente lidos por seus proprietários. Assim, também podemos acrescentar a esta problemática, que possivelmente muitos exemplares da revista $O$ Cruzeiro não foram lidos em sua totalidade. De tal feita, aqui consideramos que muitos leitores de $O$ Cruzeiro, foram também leitores da coluna Garotas, mas seria exagerado e ingênuo supor que a sua totalidade.

O periódico semanal $O$ Cruzeiro era composto por mais de 100 páginas, dentre elas duas eram sempre ocupadas pelas Garotas do Alceu. Se não podemos pensar que elas foram necessariamente lidas em todos os exemplares do impresso, podemos considerar que a coluna tinha bastante aceitação por parte do público leitor. Tanto que circulou durante ininterruptos 26 anos naquela que era considerada a maior revista de variedades do Brasil de então.

\section{Os anos de ouro}

Alguns anos foram loucos, outros rebeldes, mas aqueles, aqueles foram anos dourados. Os anos dourados do breve século (HOBSBAWM, 1998). A terminologia anos dourados é utilizada para designar os anos seguintes ao término da Segunda Grande Guerra Mundial. Segundo Eric Hobsbawm, uma fase excepcional da história do mundo capitalista, para nomeá-la os franceses utilizaram "os trinta anos 


\section{Revista Brasileira de História \& Ciências Sociais - RBHCS}

Vol. $8 \mathrm{~N}^{\circ}$ 16, Julho - Dezembro de 2016

gloriosos", les trente glorieuses, e os anglo-americanos a "Era de Ouro de um quarto de século”. No Brasil, aqueles também foram considerados anos de utopia e progresso, para Mônica Almeida Kornis (2005), marcados pelo nacional desenvolvimentismo, pela estabilidade política, pelo desenvolvimento econômico e somados a aspectos sociais e culturais, igualmente relevantes no dado período. No entanto, podemos sinalizar que essa nomenclatura é romântica, uma vez que traz uma ideia de desenvolvimentismo e de utopia.

A década de 1950 marca-se por grandes mudanças no mundo ocidentalizado. Nos países europeus, e, em especial, no Japão, os tempos tinham de fato melhorado, haja vista que os anos anteriores foram marcados pelos destroços da Segunda Guerra. Os anos pós 1945, foram marcados pela recuperação da guerra, recuperação que demora a mostrar seus benefícios materiais, o que, na Grã-Bretanha, aconteceu no decorrer daquela década de 1950. Já nos Estados Unidos da América, as mudanças não foram tão perceptíveis, uma vez que os anos de guerra não destruíram tanto aquele país. No fim da guerra, os Estados Unidos, contavam com quase dois terços da produção industrial do mundo. Os impactos da recuperação econômica do segundo pós-guerra foram sentidos e vividos de maneira bastante distinta nos diferentes continentes, países e realidades. Mais para uns do que para outros. A Era de Ouro, entretanto, foi um fenômeno mundial.

O mundo industrializado expandiu-se, as cidades cresceram, assim como sua população e seu poder de consumo. A renda per capita alcançou patamares significativos principalmente na Europa e nos chamados "países em desenvolvimento".

O aumento da produção, de produtos industrializados e não-industrializados, foi acompanhado por um aumento do consumo. Produtos e bens antes restringidos a uma minoria, agora estavam ao acesso das classes médias, como, por exemplo, o setor de eletrodomésticos, viagens e turismo e até o setor cosmético. O luxo transformou-se em padrão de conforto desejável, principalmente pelas novas classes em ascensão.

Mais do que avanços e aumento nos números de produção e da economia, as mudanças puderam ser sentidas na vida cotidiana de milhares de homens e de mulheres em todo mundo ocidental. Aquelas pessoas viram suas vidas inundadas por necessidades que até então não eram tão necessárias assim. 
Conforme já referido, o Brasil também viveu aqueles anos de ouro. O segundo pós-guerra no Brasil foi marcado pelo retorno da democracia. O Brasil que após, quinze anos de Estado Novo, voltou às urnas eleitorais para escolher seus representantes. Foram anos de importantes transformações no país. Transformações que foram e continuam sendo impressas na memória de homens e mulheres. Continuam, pois, a produção de memória (Sarlo, 2007) não está apenas atrelada ao passado. O lembrar é objeto do presente. Um presente que resignifica o passado a cada instante, seja por um livro, uma minissérie, um jornal, uma peça de teatro, uma exposição, uma novela ou pelo simples fato de relembrar. Construir novamente os fatos.

Heloisa Helena Pacheco Cardoso (2007) relata que as memórias sobre aqueles anos de ouro foram e ainda são muito realimentadas pelos meios de comunicação. Os meios de comunicação parecem ter elegido os anos 50 como modelo a ser seguido. Getúlio e Juscelino ainda hoje são considerados grandes nomes e líderes nacionais.

Nas páginas da revista estudada, O Cruzeiro, é notório esse otimismo nacional e a crença na industrialização e na dita "modernidade nacional". O consumo e a ampliação do mercado nacional foram nítidos, devido ao crescimento urbano e industrial por que passavam algumas das grandes cidades brasileiras naquelas décadas centrais do século XX. Nessas cidades, uma "classe média" consolidava-se, formada, principalmente, por funcionários públicos, empresários, comerciantes e profissionais liberais. Homens e mulheres que se adaptavam a nova maneira de sociabilidade nas cidades, novas maneiras de lazer, de locomover-se, de porta-se, de vestir-se, de informar-se e, sobretudo, uma nova maneira de consumir.

Para a historiadora Ana Cristina Figueiredo (1998), a publicidade apresenta uma dinâmica, é produzida como prática social, e, por sua vez, age, também, sobre a sociedade. Os anúncios da época fazem referências ao "novo", ao "moderno", ao "inédito". De automóveis a elixires, todos deveriam ser consumidos por homens e mulheres modernas. Modernidade que, na época, segundo Renato Ortiz (1980), não era uma simples aspiração individual, era um projeto de construção de um ideal nacional.

Se a cultura de consumo no Brasil não nasceu naquele período, foi durante aqueles anos que ela amadureceu. Amadureceu juntamente com crescimento dos grandes centros urbanos, com a ampliação da classe média e a industrialização crescente. E, segundo Figueiredo (1998), somou-se à difusão do American way of life 
em um momento em que os Estados Unidos da América precisava de aliados em virtude das disputas ideológicas acarretadas pela Guerra Fria. E é nessa conjuntura que os antigos meios de comunicação, como imprensa, rádio e cinema, são redefinidos. É a partir de 1940 que se pode começar a pensar em uma cultura popular de massa no Brasil.

A renovação cultural por que passa o país, no período, é notória. As décadas centrais do século XX, em especial as que marcaram o período democrático - de 1945 a 1964 - estão interpenetradas pelo otimismo e pela esperança. Nesta fase, a sociedade brasileira acreditava estar vivendo um período ímpar da história. Naquele período, algumas coisas mudaram, outras nem tanto. Luiz Fernando Veríssimo relata que em 8 anos (1950 - 1958) o país não tinha mudado tanto quanto ele. De fato, não tinha, mas mudou. Nos "anos dourados", o Brasil era o país do novo. Da Bossa Nova, do cinema novo, do teatro novo, da arquitetura nova, da capital nova. Mas também era o Brasil do "Bom e velho Rio".

\section{As Garotas do Alceu}

As Garotas do Alceu estamparam as páginas em formato tabloide de $O$ Cruzeiro de 1938 até 1964, foram editadas semanalmente por 26 anos no mesmo periódico. Consistia em uma coluna ilustrada de mocinhas que contavam um pouco acerca da vida cotidiana, daquele Rio de Janeiro dos meados de século XX. Os textos eram vinculados aos desenhos de Alceu Penna e foram assinados por diferentes escritores ao longo dos anos de edição da coluna. Todavia a titularidade da coluna sempre foi de Alceu Penna.

Ele não foi o mentor da criatura, mas foi seu "pai". Alceu Penna4 era considerado o pai das Garotas - e, apesar de não ter sido seu mentor, foi ele que deu

\footnotetext{
4 O desenhista nasceu no dia $1^{\circ}$ de janeiro de 1915 , na pequena cidade mineira de Curvelo. Aos 11 anos, foi estudar no Colégio Interno Santo Antônio, em São João Del Rei. Segundo Gonçalo Junior, em seu livro Alceu Penna e as garotas do Brasil: moda e imprensa - 1933/1980, desde pequeno, Alceu apresentava o gosto pelo desenho. Com seus vizinhos em Curvelo, o dentista Amedet Peret e sua esposa, o menino aprendeu os primeiros rudimentos do manuseio de pincéis e de como combinar tintas para fazer aquarelas. São esses mesmos vizinhos que descobrem o daltonismo de Alceu. Aos 16 anos, Alceu perdeu o pai, e sua família começou a passar por uma crise financeira. Um ano após a morte do pai, Alceu chegou ao Rio de Janeiro, onde passou a morar com seu primo Alexandre e Maria Isabel, sua esposa. Alceu viveu por bastante tempo na casa de seus parentes, no início localizada na Rua Voluntários da Pátria e depois, na rua Visconde de Ouro Preto, ambas no bairro do Botafogo. Na cidade, iniciou o curso superior de Arquitetura na Escola Nacional de Belas Artes, que abandonaria no ano de 1937. A escolha do curso foi um meio termo encontrado por Alceu entre a vontade de seu pai e a
} 
forma e vida à ideia do então secretário da revista: Alccioly Netto. No ano de 1938, Alccioly Netto encomendou à Penna a criação de figuras femininas semelhantes às do The Saturday Evening Post, as Gibson Girls. Assim, Alceu Penna deu forma e vida a ideia de uma coluna pin-ups 5 de Alccioly Netto. "Estávamos ainda no início dos anos 30 e eu, encantado com as figuras femininas de The Saturday Evening Post, chamadas Gibson Girls, fui certo dia procurá-lo em seu modesto apartamento da Rua das Marrecas na Lapa. Sugeri que ele fizesse alguma coisa semelhante [...]” (NETTO, 1998, p.129).

A coluna Garotas circulou durante quase 30 anos nas páginas da revista $O$ Cruzeiro e era considerada a "expressão da vida moderna no Brasil", apresentava semanalmente grupos de belas mocinhas, vestidas segundo as últimas tendências da moda, conversando sobre os mais diversos assuntos. A coluna ditou modas e costumes, criou um imaginário acerca do feminino que acabou por influenciar no comportamento de gerações de homens e mulheres.

A coluna inaugura a disseminação de novos hábitos de pensamento e vida na educação de mulheres - agora modernas e urbanas. Apesar de a coluna estar inserida numa revista de variedade voltada para toda a família, um tanto conservadora, podemos perceber uma grande diferença entre as normas difundidas e aceitas pelas Garotas e pelas demais colunas voltadas para a mulher de $O$ Cruzeiro e os preceitos de outras revistas femininas da época. A construção do discurso tanto textual quanto iconográfico na coluna é no mínimo muito mais permissível. Novos valores foram aos poucos propagados, começando a surgir um imaginário acerca de uma mulher moderna.

\section{O Rio de Janeiro nos anos dourados}

sua. Durante 5 anos ele cursou Arquitetura, mas sempre freqüentando como ouvinte o curso de Artes Plásticas.

5 "Pin-ups" quer dizer literalmente garota colada na parede. As Pin-ups têm origem nos ousados cartões-postais franceses e alemães da segunda década do século XIX. Essas características começam a aparecer nos desenhos de Raphael Kircner, na francesa La vie Parisienne, e aos poucos começam a ilustrar calendários. Os cartazes de Toulouse Lautrec são um dos primeiros exemplos de pin-ups, naqueles pôsteres impressos em litografia no século XIX já existe a imagem de uma mulher em pose sensual. Ainda no final do século XIX, elas chegam aos Estados Unidos da América, e nas primeiras décadas do século XX, começam a brilhar nas páginas de revistas americanas, transformando-se em um ícone do desenvolvimentismo americano. Tornaram-se muito populares principalmente após a Segunda Guerra Mundial, sendo consideradas um marco na imprensa do século XX. São muitos os ilustradores americanos se consagraram com suas pin-ups, como Charles Dana Gibson e Gil Elvgren 
A cidade do Rio de Janeiro dos anos dourados. A cidade cantada, contada, ilustrada, sonhada, imaginada; a cidade que não existe mais; e talvez nunca tenha existido. A cidade carioca durante os anos do segundo pós-guerra de fato existiu. Entretanto, aqui não se busca a cidade que se perdeu no tempo, busca-se, sim, suas representações. Representações que continuam a permear o imaginário de homens e mulheres. O Rio da Bossa Nova, do Samba Canção, da Cinelândia, da Confeitaria Colombo, do Teatro Municipal, dos Bailes do Copa, dos Cassinos da Urca, das areias ainda não aterradas da Baía de Guanabara. O Rio das douradas Garotas do Alceu.

O ilustrador Alceu Penna viveu boa parte de sua vida na cidade carioca, ali consagrou-se como ilustrador e figurinista. Penna formou uma teia de relações sociais no Rio de Janeiro, construiu-se como indivíduo inserido em um todo social “(...) o indivíduo sempre existe, no nível mais fundamental, na relação com os outros, e essa relação tem uma estrutura particular que é específica de sua sociedade. Ele adquire uma marca individual a partir da história dessas relações" (ELIAS, 1994, p.31). É na rede humana da cidade que ele cresce e vive como profissional. A sociedade carioca pode ser vista reverberada em seus trabalhos, nos croquis, nas propagandas e principalmente nas suas Garotas.

"Nessas décadas o Rio vivia um privilegiado momento na vida artística, de vida noturna, plena de bares e boates [...] e efervescência de sua vida cultural, atraindo artistas que se aspiravam à fama por meio principalmente do rádio e da mídia a ele associada" (MENEGUELO, 1996, p.43). Naquela cidade, estavam estabelecidas as principais editoras, sede de rádios, revistas e da televisão. Eram apresentados os mais conhecidos espetáculos, peças de teatros, desfiles. Enfim, fundiam-se as principais atividades culturais do país, no momento em que se consolidava a formação de um mercado cultural6. O Rio era a cidade mais divulgada do país, a cidade mais vista e quista do território nacional. Suas praias, cinemas, cassinos, teatros eram tidos como urbanos e modernos. "O Rio passa a ditar não só as novas modas e comportamentos, mas acima de tudo os sistemas de valores, o modo de vida, a sensibilidade, o estado

\footnotetext{
${ }^{6}$ No período pesquisado, segundo, Renato Ortiz, visualiza-se a consolidação de um mercado cultural. Nesse momento desenvolve-se um maior interesse pela temática da sociedade de massa. Segundo o cientista político o Brasil desses anos, 1945 a 1964, realmente vive um processo de renovação cultural. $\mathrm{O}$ crescimento da classe média e a concentração da população em grandes centros urbanos vão permitir a criação desse espaço cultural onde bens simbólicos passam a ser consumidos por um público cada vez maior. A partir da década de 1960 a fusão desenvolvimento do capitalismo e da crescente industrialização acarretou o aparecimento de uma indústria de bens culturais no Brasil. In: ORTIZ, Renato. A Moderna tradição brasileira. São Paulo: Editora Ática, 1980, p.81.
} 


\title{
Revista Brasileira de História \& Ciências Sociais - RBHCS
}

Vol. $8 \mathrm{~N}^{\mathrm{o}}$ 16, Julho - Dezembro de 2016

de espírito e as disposições pulsionais que articulam a modernidade com uma experiência existencial e intima" (SEVECENKO, 1998, p.522).

Ao longo da trajetória das Garotas do Alceu, a cidade deixou de ser o centro político e o econômico do país, mas não deixou de ser o cultural. Além do mais, as próprias personagens de Penna contribuíram para essa visão da cidade. Visto pela coluna o Rio era, além de tudo, a cidade das mais belas mulheres. "Pelas páginas de $O$ Cruzeiro, o país botou na cabeça que, além de metrópole e centro gerador de cultura, hábitos e modismos, o Rio tem também as mulheres mais bonitas. Como um lugar poderia ter tudo? O Rio tinha. E Alceu revelava o lado mais bonito disso: o feminino" (GONÇALO,2004, p.14).

Esses anos dourados são marcados por uma modernidade no Brasil. Mesmo sendo São Paulo o principal centro industrial, o Rio de Janeiro, a capital da República, ainda era considerado uma espécie de vitrine cultural para o restante do país. No Rio, projetavam-se os mais famosos pintores e pintoras nacionais, os atores e as atrizes de maior renome, estavam as gravadoras de discos, as emissoras de rádio. Além de ali serem produzidos os espetáculos grandiosos, eram também editados os maiores jornais e as maiores revistas brasileiras. Existia à época a ideia de que para alcançar qualquer notoriedade em temos nacionais precisar-se-ia passar antes pela cidade do Rio de Janeiro. Não era apenas a cidade do Rio a vitrine da modernidade; o homem e a mulher carioca também o eram.

\section{As Garotas cariocas}

\begin{abstract}
As cariocas de classe média e alta, nesta época, acompanhavam (e inventavam) a moda e eram consideradas mais atrevidas e liberadas que as de outras regiões do país - a vida nas praias (onde o amor é mais livre), o contato com os estrangeiros, os recursos e atividades da metrópole, então capital do país, contribuíram para comportamento e modos de pensar diferenciados. Estas garotas cariocas serviram de modelo às garotas de revistas (BASSANEZI, 1995, p.246).
\end{abstract}

As cariocas eram consideradas as mais ousadas. Um ponto que diferenciava bastante a representação da vida cotidiana destas em comparação com a vida levada pelas paulistas era a questão climática. Segundo Cristina Meneguello (1996), a representação da carioca estava diretamente associada à praia, ao sol, ao mar. Já a da paulista estava atrelada ao frio, à vida corrida da metrópole. Estas questões "contaminavam" a representação das relações. "Podia-se contar com charges de 


\section{Revista Brasileira de História \& Ciências Sociais - RBHCS}

Vol. $8 \mathrm{~N}^{\circ}$ 16, Julho - Dezembro de 2016

revistas da época enfatizando a distinção entre o namoro das cariocas, repleto de beijos, e o namoro das paulistas, com namoros sentados em bancos de praças tiritando de frio" (MENEGUELLO, 1996, p.48).

Rosane Schmitz Fernandes (2008) escreve acerca da coluna As Garotas de São Paulo e aborda a questão do corpo feminino vestido pela moda e corpo construído pela cidade. Na coluna, segundo Fernandes, as personagens ilustradas por Alceu "[...] corroboram com a construção cultural no modo de vestir-se, ocidental, brasileiros, paulistano, mas influenciados pelo estilo europeu” (FERNANDES, 2008, p.49). Aqui pontuamos que apenas nesta única coluna o ilustrador aborda essas Garotas de São Paulo, assim como em uma outra ele faz referências às Garotas dos mares do sul7. Embora constante a referência de Garotas de outros locais, como também de outras temporalidades, os locais de sociabilidade frequentados por suas bonecas, assim como as inúmeras referências bibliográficas, nos levar a crer que elas eram, de maneira geral, Garotas cariocas.

O velho Rio das Garotas, a cidade que pode ser vista e analisada sob múltiplas lentes. O passado nada mais é do que um texto ou uma imagem. É esta a perspectiva desse texto, pautado nas premissas de Maria Izilda Santos de Matos e Sandra Jatahy Pesavento (2007), que buscam perceber as questões urbanas interpenetradas numa pluralidade de fontes. "Assim, seja em documentação oficial [...], seja nos comentários dos periódicos, nos artigos e nas crônicas do cotidiano [...] os saberes se cruzam e se defrontam, ao tomar a cidade como objeto de preocupação, de elaboração, de conceitos e execução de práticas” (PESAVENTO, 2007, p.19).

O objeto analisado: a coluna Garotas está significativamente afastada da documentação oficial. Temos que ponderar dois fatores: primeiro, traz imagens e textos que circulam diariamente nas mãos dos brasileiros da época, e sobre a vida cotidiana desses; segundo, não tinha a visível pretensão de narrar a cidade. As protagonistas eram as bonecas, e não o cenário urbano. A cidade é descortinada para todo o Brasil por meio dos diálogos e cenários, sutilmente traçados por Alceu. Uma visão um tanto idealizada da Cidade Maravilhosa em seus esplêndidos anos dourados. Sandra Pesavento (2007) escrevera acerca das tantas cidades imaginárias, que muitas vezes correspondem as ditas cidades reais, táteis e concretas. A

\footnotetext{
7 A coluna As Garotas dos Mares do Sul circulou na Revista O Cruzeiro no ao de 1954, de 24 de abril, pg. 30 e 31 com textos de A. Ladino e ilustrações de Alceu Penna.
} 


\section{Revista Brasileira de História \& Ciências Sociais - RBHCS}

Vol. $8 \mathrm{~N}^{\mathrm{O}}$ 16, Julho - Dezembro de 2016

historiadora abordara o urbano como obra humana máxima constantemente reconstruída, ora pelo pensamento, ora pela ação.

O Rio de Janeiro nas páginas da coluna Garotas fora, de tal feita, um cenário ilustrado e narrado por Alceu Penna. Contudo, a cidade imaginária da coluna correspondia a cidade tátil carioca daquele Brasil de outrora. Os espaços, sobretudo urbanos do Rio, foram ressaltados de uma forma bastante romântica pelo desenhista da coluna. O Rio de Janeiro era a cidade na qual o desenhista e os escritores da coluna habitavam, bem como a cidade em que figurava a sede do grupo dos Diários dos Associados. A mudança da capital da república para Brasília fora, à principio, bastante criticada em muitas páginas da revista $O$ Cruzeiro, entre elas as ocupadas pela coluna Garotas.

\section{As Garotas não vão à Brasília}

As Garotas estão apavoradas com essa história da breve mudança da Capital. Como é que pode? Em Brasília, haverá praia, cinema empenca, festas, piqueniques, buates e clubes? Senão, como é que vai ser? Assim no escuro as garotas não vão. Farão finca-pé e permaneceram na Cidade Maravilhosa, não obstante a falta d’água, excesso de filas e o preço dos sapatos marca qualquer Luís (As Garotas não vão a Brasília. O Cruzeiro. 5 de julho de 1957).

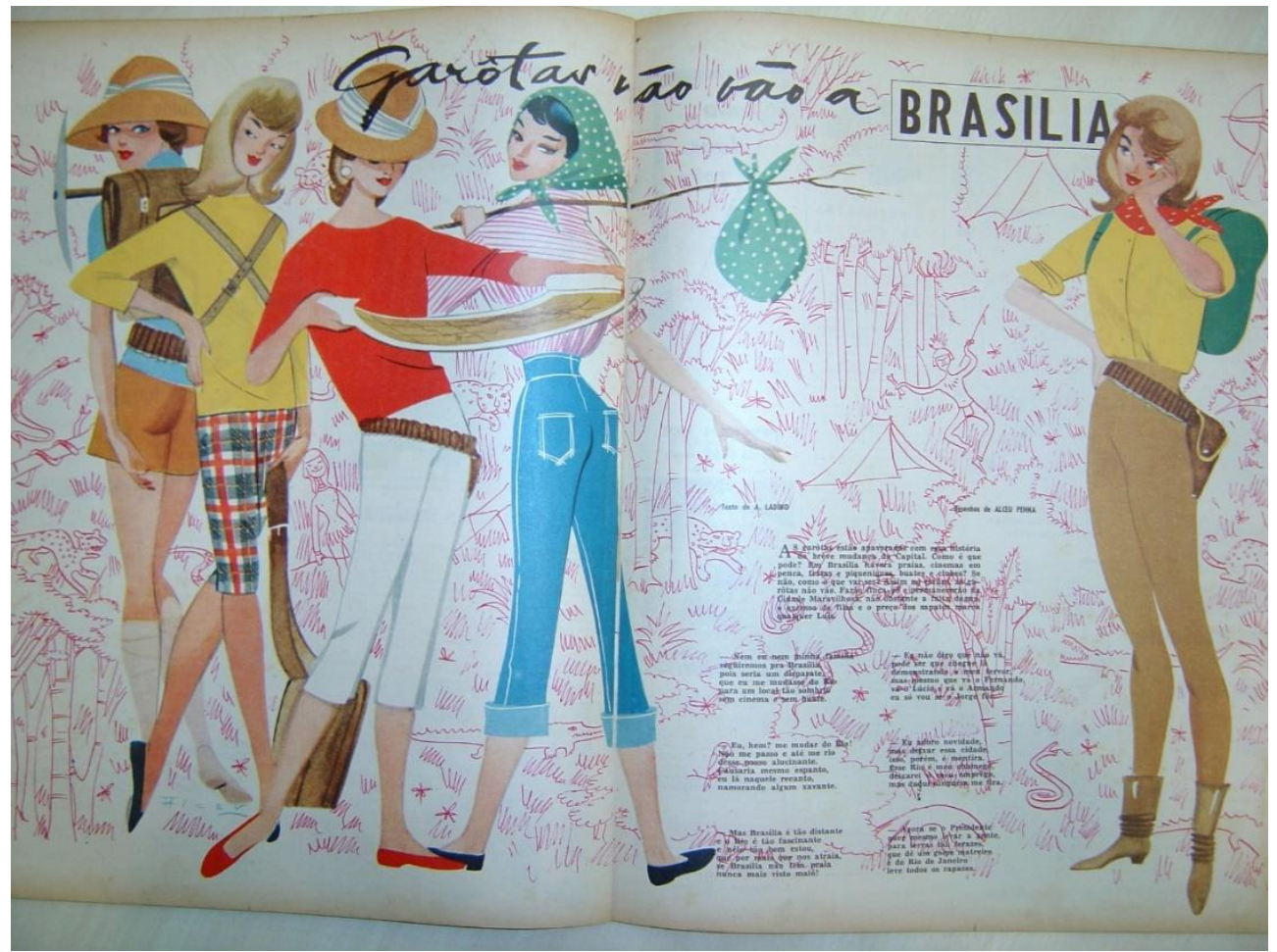

Figura 1 - Garotas não vão a Brasília - Revista O Cruzeiro 5 de julho de 1957. Acervo: Biblioteca Pública do Estado de Santa Catarina, Florianópolis/SC. 
A citação é parte integrante da coluna intitulada As Garotas não vão a Brasília, que circulou no ano de 1957. Período em que a nova capital federal estava sendo construída. Com a finalização das obras e a transferência da capital, muitas famílias tiveram que se deslocar da cidade do Rio, a fim de acompanhar alguns de seus integrantes, na grande maioria das vezes, o patriarca. As Garotas do Alceu, assim como muitos outros habitantes da cidade, não ficaram satisfeitas com esta permuta. No trecho acima podemos perceber "tudo" o que o Rio tinha para os olhos de uma jovem mulher de então. As praias cujas areias eram as mais cobiçadas do Brasil, os numerosos cinemas, as mais badaladas festas, boates e clubes.

O Rio de Janeiro consolidou-se como o principal centro social do país, ditava as normas sociais de conduta desde a chegada da família real portuguesas, em 1808 (Malerba, 2000). "Além do incremento do comércio, a vinda da Corte portuguesa promoveu a europeização do Rio de Janeiro, o que criou novas experiências para a "boa sociedade"” (RAINHO, 2002, p.53).

Segundo Rainho (2002), a mudança dos integrantes da dinastia de Bragança obrigou a sociedade carioca a "civilizar-se", observa-se, assim, a europeização de suas condutas sociais e veste. "Como a maior "cidade colonial" do Império, sede da Corte, o Rio de Janeiro era também a porta de entrada às ideias novas, concebidas no bojo do processo de renovação urbana que acompanhou a emergência da modernidade" (PESAVENTO, 2002, p.165). E aquela cidade que desde então consolidou-se como modelo para as demais de todo país, continuou assim sendo vista no período aqui estudado, meados do século XX. "No Brasil, no período estudado, esse papel de metrópole-modelo recai sem dúvida sobre o Rio de Janeiro, sede do governo, centro cultural, maior porto, maior cidade, cartão de visita do país, atraindo tanto estrangeiro quanto nacionais" (SEVECENKO, 1998. p.522).

Os primeiros manuais de civilidade, bem como demais livros, as primeiras revistas femininas, assim como outras afins, eram editados na cidade carioca. A partir daquele ponto geográfico, os hábitos e costumes europeus começam a ser disseminados pelo Brasil. E, principalmente, começam a emergir conceitos de ser moderno e urbano nos trópicos. Pois os habitantes daquela cidade de outrora frequentaram cafés, o Teatro Municipal, o Jóquei Club, mas também passavam tardes bronzeando-se a beira-mar. Ou seja, novas maneiras de condutas são reimpressas 


\section{Revista Brasileira de História \& Ciências Sociais - RBHCS}

Vol. $8 \mathrm{~N}^{\circ}$ 16, Julho - Dezembro de 2016

naquelas trazidas do Velho Mundo, ambas se interpenetram e passam a conviver cordialmente.

A Coluna Garotas estampa, muito bem, esta mescla de condutas e costumes. Ao analisar a variedade de temas que a coluna abordou, é notável a presença de costumes ainda muito afrancesados, mas também já existe a marcante presença norte americana, bem como a consolidação e a impressão de valores e costumes mais brasileiros e principalmente cariocas ${ }^{8}$. Pois "Apesar da Revista "O Cruzeiro" circular nacionalmente, Alceu Penna desenha suas "Garotas" como cariocas, inspirando-se na cidade e no estilo de vida de seus habitantes" (PENNA, 2007, p.24).

Alceu, assim como suas Garotas, encontrava-se transladado por hábitos e costumes estrangeiros. Hábitos e costumes principalmente norte-americanos e franceses. Para Renato Ortiz (1980), a década de 1940 marca uma modificação na orientação de modelos estrangeiros no país. Os costumes, os hábitos, os padrões americanos vão aos poucos tomando o lugar dos franceses. Os padrões transmitidos pela publicidade, pelo cinema, pelos livros e pelas revistas modificam-se principalmente no segundo pós-guerra. Os filmes e as estrelas de Hollywood vão aos poucos tomando o lugar dos europeus. Do mesmo modo os livros de língua francesa vão cedendo lugar nas prateleiras aos de língua inglesa.

É notória a crescente influência americana no período citado. Cristina Meneguello (1996) aborda a questão da influência hollywoodiana na vida dos habitantes das grandes cidades, onde boa parte da população frequentava as salas de cinema. "A referência a filmes, atores e atrizes desse período ainda mostrava a vitalidade própria de Hollywood, por meio da remissão saudosa a beijos-clímax entre o "mocinho" e a "mocinha" e ao vestido de Grace Kelly ou ao tailleur de Gene Tierney, atentamente copiados” MENEGUELO, 1996, p.13). Para Gerson Moura (1993), a influência maciça norte americana no Brasil começou no início da década de 1940. Segundo o historiador, a influência econômica era bem anterior, entretanto, menos visível do que a cultural. Assim conforme já explicado, as influências nos padrões de comportamento, consumo, expressões artísticas, veículos de comunicação, conhecimento técnico e científico começam a ser mais notórias a partir de 1940. "Talvez a maior vitória do Tio Sam tenha sido a de convencer boa parcela da

\footnotetext{
8 É marcante nas páginas da coluna Garotas costumes e comportamento brasileiros e principalmente cariocas. Entre eles destacam-se hábitos de sociabilidade na praia, por exemplo. As normativas em namoros e saídas também são bastantes particulares nas páginas daquela coluna.
} 


\title{
Revista Brasileira de História \& Ciências Sociais - RBHCS
}

Vol. $8 \mathrm{~N}^{\circ}$ 16, Julho - Dezembro de 2016

sociedade brasileira da "modernidade" de seus valores, de suas atitudes, de seu saber científico e técnico [...]” (MOURA, 1993, p.82). Em contraste com os valores, atitudes e saberes brasileiros considerados "atrasados".

Entretanto, também é inegável que o modelo, a cultura, a língua francesa ainda continuavam atrelados à tradição e ao bom gosto. Segundo Mara Rubia Sant'Anna (2005), Paris ainda permanece como vitrine do belo e do feminino, como capital do bom-tom e do bom-gosto, a capital francesa permanece como capital das elites. Principalmente, numa cidade como o Rio de Janeiro - a antiga capital do império. Hábitos, costumes e condutas transformam-se. Todavia, esta permuta se dá de maneira mais lenta e pausada. Por exemplo, o próprio Alceu Penna que, muito embora tenha viajado e permanecido por algum tempo nos Estados Unidos da América ilustra suas Garotas sob maciça influência europeia, sobretudo francesa. Até nos tempos de agora, século XXI, Paris permanece como capital da alta costura. As colunas de moda assinadas semanalmente na Cruzeiro e mensalmente na Cigarra eram, em sua grande maioria, referente aa estilistas franceses e italianos. As Garotas vestiam-se seguindo as tendências de moda difundidas por Alceu Penna e, por consequência, seguindo as tendências dos grandes costureiros franceses. A predominância da influência francesa é notória na representação das Garotas.

\begin{abstract}
Alceu Penna, jornalista responsável, diversos anos, por difundir e noticiar os lançamentos da Alta-costura francesa, no Brasil, através da Revista O Cruzeiro, atribuiu a Paris e ao seu primeiro produto de exportação a "Glória de todo o mundo". Para Penna, a Alta-costura era a maior de todas as artes, reunidas na Capital-luz (...) (SANT'ANNA, 2005, p.295).
\end{abstract}

Como Mara Rúbia Sant'Anna (2005) escreveu no texto acima citado, Alceu Penna foi, durante anos o jornalista responsável pelas colunas de moda da revista $O$ Cruzeiro. Nestas colunas, Alceu ilustrou e escreveu ${ }^{9}$ sobre os novos ditames da Altacostura parisiense. Por tal motivo, a coluna da secção de humor também assinada por ele, na mesma revista, estava interpenetrada de modas e modos considerados afrancesados. As vestimentas das Garotas seguiam as tendências assinaladas pelos estilistas franceses, e os modos convergiam aos ditames dos Manuais de Civilidade de mesma nacionalidade.

Todavia, se as Garotas vestiam-se seguindo os ditames da moda francesa, elas utilizam vocabulário repleto de palavras inglesas, viajavam seguidamente para Nova 


\section{Revista Brasileira de História \& Ciências Sociais - RBHCS}

Vol. $8 \mathrm{~N}^{\mathrm{o}}$ 16, Julho - Dezembro de 2016

Iorque e adoravam os atores de Hollywood. A referência a padrões e hábitos estrangeiros é muitíssimo recorrente na coluna estudada. Porém, não se consolida como privilegio da mesma. Folheando as mais diferentes revistas do Brasil na época, notam-se ali impressas referências bastante similares. Fotonovelas, reportagens, quadrinhos, publicidades parecem estar inundados desses valores “de fora”.

"Entre os argumentos utilizados pela publicidade comercial para conferir respeitabilidade às empresas anunciantes, foram frequentes as referências aos valores e padrões estrangeiros, quase sempre norte-americanos ou europeus" (FIGUEIREDO, 1998, p.49). Ana Cristina Figueiredo atrela essa constante da publicidade ao antigo hábito de se consumir produtos estrangeiros. Em um país em que a muito pouco tempo atrás boa parte do que se consumia de produtos industrializados não era aqui produzido, não poderia ser diferente. O nacional era firmado por valores e padrões estrangeiros. Jeffrey Needell (1993) investiga sobre a influência francesa no país durante a Bela Época, em que para ele ocorreu uma chamada "identidade fora do lugar", uma vez que no Brasil costumes de um passado europeus são apropriados com se estivessem arraigados a sua “tradição".

\section{Tem cada Garota em Copacabana}

Não obstante, não apenas de referências estrangeiras eram feitas na coluna. A personagens festejaram o 7 de setembro, dançaram o carnaval e foram a muitas praias cariocas. Um dos assuntos bastante recorrentes na coluna era a praia. $\mathrm{O}$ ir à praia, o banho de mar, o bronzear-se era considerado saudável e moderno. Entre as praias mais frequentadas pelas polianas estava a boêmia Copacabana. Copacabana que, para além da praia, era um bairro "granfa"10, com uma vida artística e boêmia bastante movimentada. A historiadora Maria Izilda Santos de Mattos, no livro Dolores Duran: experiência boêmia em Copacabana nos anos 50 (2005), aborda as questões da sociabilidade deste bairro carioca na década de 1950. Segundo Santos de Mattos, no bairro é notável a presença de “(...) um novo modelo de mulher, vinculada ao estilo moderno e urbano de viver Copacabana (...)” (MATTOS, 2005, p.114). A mulher que começa a sair à noite, que aprecia bebidas alcoólicas. As Garotas, por mais que estivessem vinculadas ao ideal de boas moças, apresentavam-se inseridas

${ }^{10}$ Gíria da época, referente a granfinas,sofisticada. 


\section{Revista Brasileira de História \& Ciências Sociais - RBHCS}

Vol. $8 \mathrm{~N}^{\mathrm{O}}$ 16, Julho - Dezembro de 2016

nesta realidade "moderna" carioca. Na coluna intitulada Tem cada garota em Copacabana..., um dos versinhos diz o seguinte:

No bar não te arrisque com refrescos - beberagens garota dessas paragens

é bebedoura de uísque (Coluna Tem cada garota em Copacabana.... Revista O Cruzeiro de 5 de janeiro de 1953). ${ }^{11}$

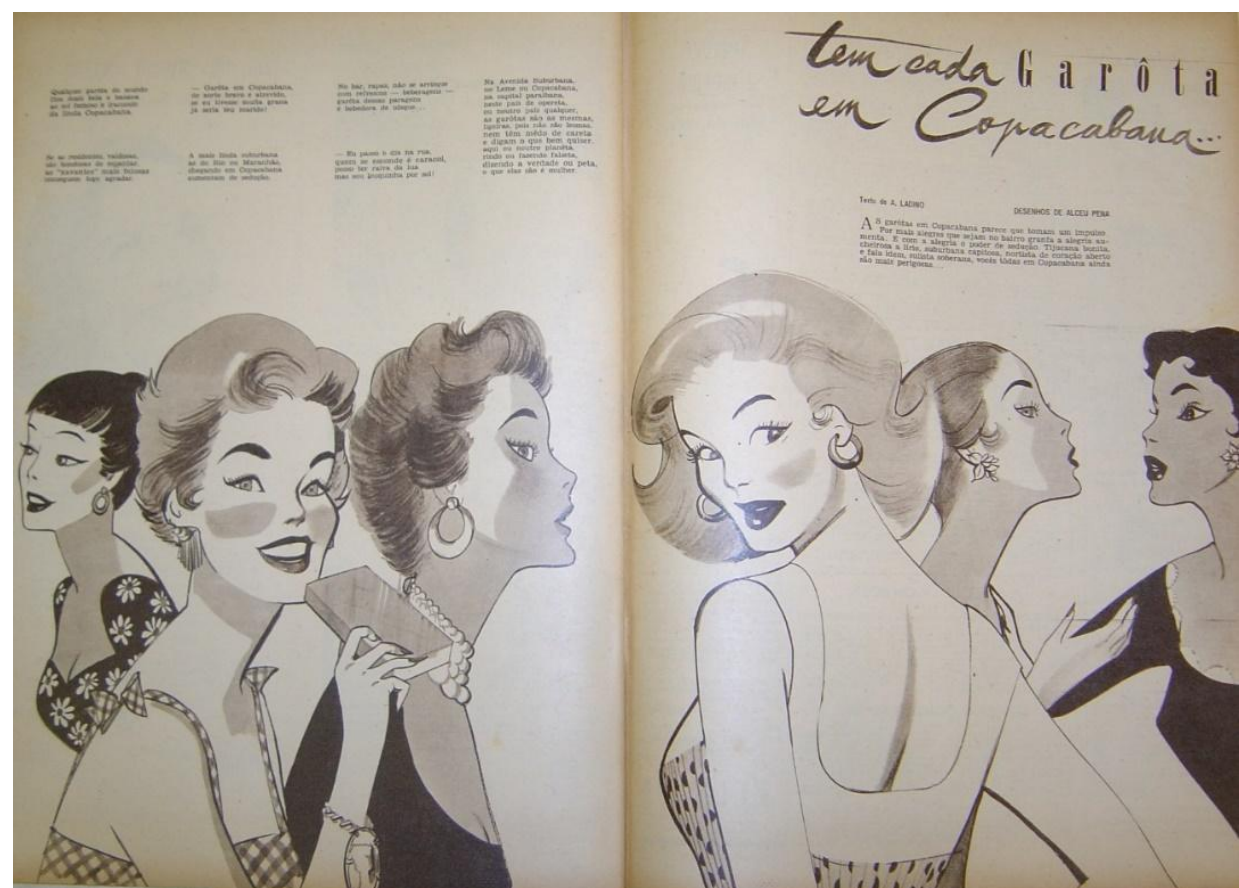

Figura 2 - Coluna Garotas - Tem cada Garota em Copacabana - Revista O Cruzeiro 5 de janeiro de 1953. Acervo: Biblioteca Pública do Estado de Santa Catarina, Florianópolis/SC.

Na coluna de 1953, as Garotas de Copacabana são adjetivadas como alegres, bonitas, atrevidas, dotadas de grande poder de sedução e, como se pode ver acima, bebedouras de uísque. E esta não é a única referência a "beberagens" das Garotas, existem outras, como a Garotas e Uísque, e $A$ ressaca das Garotas. Como se pode perceber na imagem acima, as colunas dificilmente traziam seus cenários ilustrados. Algumas vezes apareciam objetos, como automóveis, livros, ou alguns poucos elementos como o mar. Logo, a cidade do Rio de Janeiro em si não foi ilustrada nas colunas pesquisadas, mas inúmeras referências são feitas a ela, como podemos perceber nas colunas aqui colocadas.

As bonecas ilustradas por Alceu percorreram os mais diversos cenários. Entretanto, devemos pontuar que locais como fazendas eram visitados apenas 


\section{Revista Brasileira de História \& Ciências Sociais - RBHCS}

Vol. $8 \mathrm{~N}^{\circ}$ 16, Julho - Dezembro de 2016

durante as férias ou os finais de semanas. As Garotas eram, sem dúvida, personagens da vida urbana. Dentro da cidade, de maneira geral, as personagens movimentavamse nos mais diferentes lugares de sociabilidade da época. Até mesmo em locais não aconselhados para jovens mulheres. A sociabilidade da mulher no espaço público ao longo de séculos foi um assunto bastante problemático. Segundo Michelle Perrot, "O lugar das mulheres no espaço público sempre foi problemático, pelo menos no mundo occidental que desde da Grécia antiga pensa a cidadania e constoi a política como núcleo de decisão e poder" (PERROT, 1997, p. 8). No Brasil da década de 1950, uma moça de família, não deveria frequentar certos cenários urbanos, como bares e afins, entretanto as Garotas percorrem esses lugares mal afamados da urbes, sem que com isso deixassem de se enquadrar no ideal de boa moça. A permissibilidade dada às bonecas de Alceu deve-se a dois importantes fatores. Primeiro, elas eram personagens, Garotas de papel, diferentemente de suas leitoras. Segundo, eram personagens de uma secção de humor, era a “subversão pelo riso” (Soihet, 1998).

\section{As Garotas cariocas}

Nos anos dourados, em especial na cidade do Rio de Janeiro, os padrões de comportamentos femininos não são unívocos. E as personagens de Alceu Penna parecem estar diante desta dualidade, entre moças de família e moças faladas. Que, a partir daqueles tempos, passam a não estarem tão presas assim a estes termos duais. A "mulher moderna brasileira" de meados do século XX começa a conquistar novos espaços. E, por produzir uma coluna de humor, Alceu relata um pouco daquele universo em que viveu. Um universo rodeado de mulheres dos mais diferentes tipos, assim como seus trabalhos.

Um homem que, na cidade do Rio de Janeiro, esteve rodeado de quadrinhos, vestidos, colunas, tipos e mulheres. Desenhava de vestidos de noivas a fantasias de shows para cassinos. Ilustrava de colunas de culinária a cartazes de boates. Suas personagens são um pouco de tudo isso, bebem, tem ressacas, fazem compras, vão à praia, ao cinema, leem, estudam, frequentam cursos de policultura, namoram vários garotos, dirigem, fumam, e sonham com um bom casamento. Talvez porque a coluna não seja apenas garota, mas sim Garotas. Ilustra e escreve sobre as vidas das mulheres cariocas daqueles anos dourados. Mulheres como Dolores Duran, que, por mais que vivesse uma vida totalmente boêmia, não conseguia se desvincular do 
Revista Brasileira de História \& Ciências Sociais - RBHCS

Vol. $8 \mathrm{~N}^{\mathrm{o}}$ 16, Julho - Dezembro de 2016

ideário do amor romântico. Eram apenas Garotas. Embebedadas pela cidade carioca de outrora. Eram as Garotas do Velho Rio.

\section{BIBLIOGRAFIA}

BASSANEZI, Carla Beozzo e URSINI, Lesley Bombonatto. O Cruzeiro e as Garotas. In: Cadernos Pagu (4) 1995.

CARDOSO, Heloísa. Os "anos dourados": memória e hegemonia. In: Revista de História Cultura e Artes, vol. 9 n.14. Uberlândia, 2007.

COELHO, Andrea e RODRIGUES, Denise dos Santos. Cadernos da Comunicação Série Memória. O Cruzeiro: a maior e melhor revista da América Latina. Série Estudos, vol. 5, Rio de janeiro, 2002.

CHARTIER, Roger. A aventura do livro: do leitor ao navegador. São Paulo: Editora Unesp, 1999.

CHARTIER, Roger. Leituras e leitores na França do Antigo Regime. São Paulo: Editora Unesp, 2004.

ELIAS, Norbert. A sociedade dos Indivíduos. Rio de Janeiro: Jorge Zarah Editor, 1994 .

FERNANDES, Rosane Schmitz. Garotas de São Paulo: imagem de um corpo vestido pela moda. In: Moda Palavra e-periódico. Ano 1, $\mathrm{n}^{0}$ 2, ago- dez 2008.

FIGUEREDO, Ana Carolina Camargo Moraes. Liberdade é uma calça velha azul e desbotada. Publicidade, cultura de consumo e comportamento político no Brasil (1954-1964). São Paulo: Hucitec, 1998.

HOBSBAWM. Eric. A Era dos Extremos: O breve século XX 1914-1991. São Paulo. Companhia das Letras, 1998.

GONÇALO, Junior. Alceu Penna e as Garotas do Brasil: Moda e imprensa 1933/1980. São Paulo: CLUQ - Clube dos Quadrinhos, 2004.

MALERBA, Jurandir. A corte no exílio; civilização e poder no Brasil às vésperas da Independência (18o8-1821). São Paulo: Companhia das Letras, 2000.

MARTINS, Maria Luiza. Revistas em revista: Imprensa e práticas culturais em tempos republicanos, São Paulo (1890-1922). São Paulo: EDUSP, 2001.

MATTOS, Maria Izilda Santos de. Dolores Duran: experiência boêmia em Copacabana nos anos 50. Rio de Janeiro: Bertrand Brasil, 2005.

MENEGUELO, Cristina. Poeira de estrelas: o cinema Hollywoodiano na mídia brasileira das décadas de 4O e 50. Campinas: Editora da UNICAMP, 1996. 
MOURA, Gerson. Tio Sam chega ao Brasil: a penetração cultural americana. São Paulo: editora brasiliense, 1993.

NEEDELL. Jeffrey. Belle époque tropical. São Paulo: Companhia das Letras, 1993.

ORTIZ, Renato. A Moderna tradição brasileira. São Paulo: Editora Ática, 1980.

KORNIS, Mônica Almeida. A era da Bossa Nova: Anos Dourados? Revista Nossa História. São Paulo, n²3, ano II, p.26-29, set. 2005.

PENNA, Gabriela Ordones. Vamos Garotas! Alceu Penna, moda, corpo e emancipação femininas (1938-1964). Dissertação de Mestrado em Moda, Cultura e arte. Centro Universitário SENAC, 2007.

PESAVENTO, Sandra Jatahy. Cidades visíveis, cidades sensíveis, cidades imaginadas. Revista Brasileira de História. Vol.27, nº 53, jan-jun, 2007.

PERROT, Michelle. Mujeres en la ciudad. Santiago de Chile: Editorial Andres Bello, 1997.

PESAVENTO, Sandra Jatahy. O imaginário da cidade: visões literárias do urbano Paris, Rio de Janeiro, Porto Alegre. Porto Alegre: Ed. Universidade / UFRGS, 2002.

RAINHO, Maria do Carmo Teixeira. A cidade e a moda: novas pretensões, novas distinções - Rio de Janeiro, século XIX. Brasília: Editora da Universidade de Brasília, 2002.

SANT'ANNA. Mara Rúbia. Aparência e Poder: novas sociabilidades urbanas em Florianópolis, de 1950 a 1970. Tese de doutoramento em História defendida na UFRGS. Porto Alegre, 2005.

SARLO. Beatriz. O Tempo Passado: cultura da memória e guinada subjetiva. São Paulo: Companhia das Letras, Belo Horizonte: Editora UFMG, 2007.

SERPA, Leoní. A máscara da modernidade: A mulher na revista O Cruzeiro (19281945). Passo Fundo: Editora UPF, 2003.

SEVECENKO, Nicolau. A capital irradiante: técnica, ritmos e ritos. In: História da Vida Privada no Brasil vol. 3. São Paulo: Companhia das Letras, 1998.

SILVA, Marcos Antônio da. Prazer e poder do amigo da onça 1943-1962. Rio de Janeiro: Paz e Terra, 1989.

SOIHET, Rachel. A Subversão pelo riso: Estudos sobre o carnaval carioca da Belle Époque ao tempo de Vargas. Rio de Janeiro: Editora Fundação Getúlio Vargas, 1998. 